\title{
Gestão do Conhecimento nas
Organizações Públicas Brasileiras \\ - Diagnóstico em uma Instituição Federal de Ensino
}

Knowledge Management in Brazilian Public Organizations - Diagnosis in a Federal Educational Institution

\author{
Paula Peres (D) \\ ISCAP, P.Porto, Portugal \\ pperes@iscap.ipp.pt \\ Vilson Rafael Batista (D)
} Instituto Federal de Educação, Ciência e Tecnologia de Rondônia vilson.rafael@ifro.edu.br 


\section{Resumo}

O conceito de Gestão do Conhecimento (GC) está compreendido essencialmente no nível estratégico das organizações. O seu estudo é considerado um recurso relativamente novo às organizações públicas e privadas no Brasil. Neste trabalho de investigação, inicialmente foi realizado um estudo bibliográfico por meio de Revisão Integrativa da literatura e, num segundo momento, realizou-se um trabalho empírico de abordagem qualitativa por meio do estudo de caso como metodologia de investigação e utilizou-se a entrevista com questões semiestruturadas para a coleta dos dados. A partir da revisão de literatura restou evidente que a grande maioria das organizações públicas no Brasil ainda não possuem modelos ou práticas de GC instituídas. Os resultados do estudo empírico permitiram concluir que o Departamento investigado realiza alguns tipos de práticas simples de GC, mas são práticas aleatórias, alternadas e não intencionais. Acredita-se que as contribuições do estudo serão muito úteis a gestores de organizações públicas no país com foco nos princípios da eficiência da Administração Pública.

Palavras-chave: Gestão do Conhecimento, Organizações públicas, Práticas de Gestão do Conhecimento, Valor competitivo.

\section{Abstract}

The concept of Knowledge Management $(\mathrm{KM})$ is understood at the strategic level of organizations and its study is considered a relatively new strategic resource for public and private organizations in Brazil. In this research work, a bibliographic study was initially carried out by means of Integrative Literature Review and, in a second moment, an empirical work of qualitative approach was carried out by means of the case study as a study method and an interview with semi-structured questions was used to collect the data. From the literature review, it was evident that the most majority of public organizations in Brazil still do not have established KM models or practices. The results of the empirical study allowed us to conclude that the investigated Department performs some types of simple KM practices, but they are random, alternate and unintentional practices. It is believed that the study's contributions will be very useful to managers of public organizations in the country with a focus on the principles of public administration efficiency.

Keywords: Knowledge Management, Public organizations, KM practices, Competitive value. 
1. Introdução

A Gestão do Conhecimento é o conjunto de tecnologias e processos cujo objetivo é apoiar a criação, o armazenamento, a transferência e a aplicação do conhecimento nas organizações. $O$ estudo da GC trata de uma área de atuação transversal entre diversas disciplinas, sobretudo, à gestão estratégica, teoria das organizações, sistema de informação, gestão da tecnologia, e também, às áreas mais tradicionais como a economia, sociologia, psicologia, marketing (Sociedade Brasileira de Gestão do Conhecimento, 2014). O conceito de GC está inserido na visão de organização de políticas e ferramentas gerenciais com vistas a uma melhor compreensão dos processos organizacionais desde a geração até a partilha e aplicação de conhecimentos estratégicos, seja para a organização seja para os stakeholders. Conforme afirmam Braun e Mueller (2014) a administração pública contemporânea tem sido impulsionada por novos desafios e por isso tem procurado cumprir sua função social de forma cada vez mais profissional, criando mecanismos com caráter inovador para gerir e produzir conhecimento aprimorando seus sistemas e buscando novos modelos de gestão, para melhoria da qualidade dos serviços, ampliando sua capacidade de governar em busca de melhores resultados. Nos últimos anos, em todo o mundo, cada vez mais as organizações públicas e privadas têm se voltado para o estudo do tema. Nesse contexto, questiona-se: Como as organizações públicas brasileiras têm percebido esse recurso estratégico? Como o Instituto Federal de Rondônia (IFRO), instituição pública brasileira, o têm utilizado? Qual a perceção dos colaboradores acerca da GC e qual o tipo de conhecimento gerado no Departamento de Apoio ao Ensino do IFRO na unidade Campus Ji-Paraná? De que maneira é feita a gestão do conhecimento produzido pelos colaboradores? Quais recomendações podem ser úteis para 0 aprimoramento das práticas de $\mathrm{GC}$ que $\mathrm{o}$ Departamento de Apoio ao Ensino que já realiza? A partir dessas questões, a investigação teve por objetivo compreender como o Departamento de Apoio ao Ensino realiza a gestão do conhecimento produzido pelos colaboradores que trabalham no setor.

Dessa forma, o presente trabalho de investigação buscou-se reunir dados por meio de pesquisa bibliográfica e estudo empírico utilizando a metodologia estudo de caso com a finalidade de obter compreensão se de algum modo havia modelo implementado ou práticas de GC utilizadas pelo Departamento de Apoio ao Ensino do Instituto Federal de Rondônia no campus Ji-Paraná, órgão inserido na Administração Pública Brasileira. O estudo torna-se relevante e encontra justificativa em função da proeminência do tema para a gestão das organizações despertada pelo potencial de eficácia na gestão e o fato de, aparentemente, ser ainda um tema relativamente novo para as organizações públicas e privadas brasileiras. Embora numa perspetiva empírica, observa-se que a GC nas instituições públicas brasileiras parece ser algo relativamente novo e ainda bem pouco explorada tanto do ponto de vista da Gestão Organizacional como também do ponto de vista acadêmico. Diante disso, esperava-se alcançar resultados que viessem a ser úteis a gestores de organizações públicas no país, especialmente para implementação de 
práticas de Gestão de Conhecimento com foco nos princípios da eficiência da Administração Pública.

\section{Enquadramento Teórico}

\subsection{Breve conceitualização de Gestão do Conhecimento}

O estudo da GC está inserido no nível da gestão estratégica da administração e é utilizada dentro da organização para identificar um conjunto de instrumentos e processos cujo objetivo é organizar e possibilitar a criação, o processamento, a transferência e a aplicação do conhecimento nas organizações. Para (Fleury \& Oliveira, 2017), citados por Vianna et al. (2017), a GC é uma atividade que tem por objetivo identificar, desenvolver e atualizar o conhecimento estratégico relevante para a empresa, tanto por meio de processos internos, quanto por meio de processos externos. $\mathrm{O}$ conhecimento pode ser classificado quanto à sua dimensão epistemológica em dois tipos: conhecimento explícito e conhecimento implícito, ou tácito. O professor e pesquisador húngaro-britânico Michael Polanyi (1891-1976) trouxe importantes contribuições ao estudo da construção do conhecimento ao fazer uma clara e interessante distinção entre conhecimento explícito e conhecimento tácito. Nonaka e Takeuchi (1997) afirmam que, conforme Polanyi, o conhecimento tácito é pessoal e específico ao contexto sendo, assim, difícil de ser formulado e comunicado. Concluíram que ao levar em conta a teoria de Polanyi, no espectro da dinâmica de comparação dos conhecimentos tácito e explícito, o conhecimento que pode ser expresso em palavras e números, surgindo o conhecimento explícito, que representa apenas a "ponta do iceberg" no conjunto de conhecimentos. O que se depreende é que o conhecimento estratégico relevante na organização é tido como a matériaprima, que primeiramente é identificada e processada interna e externamente, e depois é utilizado em benefício da organização dando origem, desta forma, ao que se chama de processo de Gestão do Conhecimento.

\subsection{A Gestão do Conhecimento nas Organizações Públicas}

Acredita-se que as práticas de GC e os processos de gestão estratégica guiados pelo conhecimento podem ter impacto significativo no desempenho das organizações públicas. A sociedade tende a observar e avaliar a qualidade dos serviços prestados refletindo na imagem que estas criam com respeito à organização. De acordo com Silva (2018) "a sociedade está sempre exigindo uma resposta do Estado no que concerne a adoção de um modelo de gestão que consiga abordar de forma simultânea os aspetos sociais, ambientais e económicos" (Silva, 2018, p. 9). Na mesma linha, Basso (2017), acrescenta que o desenvolvimento da GC na Administração Pública "possui ainda um caráter social, não só cumpre a finalidade de melhorar o desempenho organizacional, mas também transforma o conhecimento em instrumento catalisador de inovação e produtividade, refletindo positivamente na sociedade" (Basso, 
2017, p. 8). De acordo com Paludo (2016), as organizações públicas precisam estar imbuídas de uma cultura organizacional bem definida, constituída do desejo de inovação, aprendizado

$\mathrm{e}$

comprometimento com $\mathrm{O}$ atendimento eficiente com vistas a olhar para as necessidades da sociedade como se suas fossem. Diante do exposto, percebe-se que é inequivocamente aguardado pela sociedade brasileira que a Administração Pública empreenda esforços contínuos no aperfeiçoamento da sua prestação de serviços. Não obstante, fica evidente que a corrida pelo aprofundamento de estudos e pela implantação de modelos customizados de GC é bastante urgente e bem-vinda a uma sociedade atuante na exigência de qualidade dos serviços públicos.

\subsection{Utilização da GC atualmente nas organizações públicas brasilleiras}

Em trabalho de investigação recente, Arvani (2018) argumenta que ao consideramos a GC no âmbito da administração pública, enxerga-se um propósito distinto daquele da iniciativa privada no que diz respeito às "suas especificidades, seus princípios básicos e direcionadores, o envolvimento dos atores públicos e da sociedade, bem como pela limitação de seus regulamentos" (Arvani, 2018, p. 10). Para Motta (2013), existe por parte da sociedade "pressões para mais e melhores serviços e uma expectativa de solução imediata de problemas urgentes: o público espera da administração pública o melhor atendimento de suas demandas sociais, pelo uso eficiente de recursos e transparência dos atos" Motta (2013, p. 82). Nota-se que do ponto de vista prático existe por parte da sociedade um anseio por maior eficiência e maior transparência na prestação dos serviços públicos.
Entretanto, é também percetível que a administração pública possui certa dificuldade em manter serviços de qualidade e com a agilidade necessária para se enquadrar como satisfatória face aos anseios da sociedade. À Administração Pública atribuiu-se a prestação de variados serviços públicos alçados à categoria de direitos fundamentais e, é por intermédio desses serviços que direitos fundamentais são concretizados (Setim, 2019, p. 108). Nessa mesma linha Helou (2015), assim como Arvani (2018), ao comparar a administração pública com a administração privada defendeu que "gerenciar organizações públicas é frequentemente diferente de gerenciar organizações privadas, uma vez que as primeiras produzem valores públicos que impactam a todos e, por isso, envolvem o balanceamento dos interesses dos stakeholders" (Helou, 2015, p. 74). Assim, diante das ideias expostas, argumenta-se que com o caminhar da Administração Pública brasileira em direção ao aprofundamento de estudos e à implementação de modelos de GC parece ser inegável que maximizará, ao seu tempo, sua eficiência e agilidade nos serviços a serem disponibilizados à sociedade.

Um estudo longo e bastante aprofundado de Batista e Quandt (2015), por meio do Instituto de Pesquisa Económica Aplicada - IPEA, no Brasil, trouxe importantíssimas contribuições referentes à Administração Pública brasileira no que tange a ações e práticas de GC em organizações públicas. Os autores trazem informações de investigação realizada em 2014 sobre da perceção de gestores quanto ao estágio de implantação e o alcance pretendido, no interior da organização, diversas práticas relacionadas à GC. Os resultados 
encontrados permitem afirmar que: i) em relação ao estágio de implantação de práticas de GC nas 81 organizações pesquisadas, é possível identificar três grupos distintos: O primeiro engloba 29 organizações que possuem mais de vinte práticas implantadas; o segundo grupo, temos 28 organizações que implantaram de onze a vinte práticas, e o terceiro compreende 23 organizações que implantaram dez práticas ou menos; ii) é possível constatar que as práticas vinculadas principalmente à tecnologia tendem a ser mais adotadas entre as organizações pesquisadas, enquanto as práticas ligadas a processos tendem a apresentar um nível mais baixo de implantação e; iii) o alcance é claramente mais amplo nas práticas tecnológicas, em relação às outras duas categorias. A investigação também permitiu perceber que das 81 organizações estudadas a maior parte (57 delas) possuem acima de 11 práticas de GC já implantadas e que estas práticas estão, em maior parte, vinculadas ao uso da tecnologia em contraponto com as práticas ligadas a processos que tendem a apresentar um nível mais baixo de utilização. Quanto ao alcance dessas práticas restou evidente que o alcance é maior nas práticas tecnológicas em comparação às outras duas categorias (processos e gestão de pessoas).

Os resultados do estudo de Batista e Quandt (2015) aliados a resultados de investigações recentes podem acendernos uma lâmpada pelo fato de que as organizações públicas brasileiras investigadas demonstram terem se empenhado mais em implantar práticas relacionadas à Gestão de Pessoas e à Tecnologia do que práticas relacionadas a Processos. Talvez porque teriam encontrado maiores dificuldades na operacionalização nesse tipo de prática.

\section{Metodologia}

Numa investigação científica entende-se que a metodologia a ser utilizada deve responder simultaneamente a diversas questões, de modo a deixar claro todo o escopo do estudo, bem como o caminho a ser percorrido no trabalho de investigação. Segundo Marconi e Lakatos (2003, p. 105) "A especificação da metodologia da pesquisa é a que abrange maior número de itens, pois responde, a um só tempo, às questões como? com quê? onde? e quanto?". Neste estudo, o procedimento metodológico adotado para a revisão de literatura foi o da Revisão Integrativa e para o trabalho empírico o Estudo de Caso. Conforme esclarecem Souza et al. (2010) “a revisão integrativa emerge como uma metodologia que proporciona a síntese do conhecimento e a incorporação da aplicabilidade de resultados de estudos significativos na prática" (Souza et al., 2010 , p. 102). Para atingir os objetivos da investigação, optou-se pelo método estudo de caso, na forma de abordagem qualitativa uma vez que se pretendia estudar a realidade do Departamento de Apoio ao Ensino quanto ao desenvolvimento de possíveis práticas de GC pelos colaboradores. Após observação e análise da problemática que deu origem ao tema da investigação, definiu-se os objetivos e as questões-chave e constatou-se que seria possível realizar o trabalho de investigação na instituição 
pública, local de trabalho do investigador. O que possibilitou a escolha foi o fato de ser uma instituição que faz parte da administração pública brasileira - área de investigação do presente estudo. A partir da constatação dessa possibilidade o Instituto Federal de Rondônia, Campus JiParaná, foi a instituição escolhida para esse estudo.

A documentação utilizada para a revisão de literatura compôs-se em fontes primárias e secundárias. $\mathrm{O}$ rol de fontes primárias constituiu-se em artigos científicos, legislações nacionais e os relatórios da entrevista. Como fontes secundárias utilizou-se artigos científicos, dissertações, teses e livros. Para busca dos artigos científicos utilizou-se o Sistema SciELO de Publicação, que reúne diversas revistas conceituadas, e as plataformas Elsevier e ResearchGate. Os artigos e teses encontradas contribuíram muito no sentido de trazer luz à nossa reflexão inicial por meio de estudos de casos sobre práticas, ferramentas, modelos e programas de GC implementados ou em implementação. As obras de Nonaka e Takeuchi (1997), Takeuchi e Nonaka (2008), Davenport e Prusak (1999), Stewart (1998) e Krogh et al. (2001) deram base ao referencial teórico.

A coleta de dados foi realizada no segundo semestre de 2020 entre os meses de agosto e setembro. Para Gil (2002, p. 140) "o processo de coleta de dados no estudo de caso é mais complexo que o de outras modalidades de pesquisa". Num estudo de caso, geralmente, é utilizada mais de uma técnica no processo de coleta de dados, entretanto, devido ao tempo escasso e a alta possibilidade de se conseguir entrevistar todos os colaboradores do Departamento, isto é, $100 \%$ da populaçãoalvo, optou-se por realizar nesta investigação somente as entrevistas. Para a entrevista se utilizou questões bem guiadas por meio de um roteiro semiestruturado. De fato foi possível entrevistar toda a população pretendida os 20 colaboradores que atuam no Departamento. Conforme Marconi e Lakatos (2003) o universo ou população é o conjunto de seres animados ou inanimados que apresentam pelo menos uma característica em comum. Sua delimitação consiste em deixar explicito que pessoas, coisas ou fenómenos serão investigados e que devem ser enumeradas suas características comuns. No caso deste estudo, o universo é composto por 20 colaboradores de um Departamento em uma Unidade (Campus Ji-Paraná) de uma organização pública federal (Instituto Federal de Rondônia) localizada no Estado de Rondônia, no Brasil. Para início da fase de coleta dos dados foi realizado um préteste com um dos colaboradores do Departamento a fim se sondar a consistência do guião. $\mathrm{O}$ guião foi planeado e elaborado pelo investigador a partir dos conceitos e teorias levantadas na revisão de literatura, valendo-se, principalmente, das contribuições de Pinto (2015) e Magalhães (2017). Após análise do pré-teste verificou-se que o guião estava adequado para a entrevista, cujo objetivo era verificar e conhecer a real situação do Departamento investigado acerca das possíveis práticas de GC desenvolvidas, não necessitando de reformulação no guião. Devido à situação de isolamento social imposta pela pandemia do Covid-19 as entrevistas foram realizadas de forma virtual e gravadas em vídeo por meio do aplicativo de videoconferência Google Meet. As falas dos participantes foram gravadas em áudio e vídeo e posteriormente transcritas 
para uma tabela em documento no formato Excel.

Para análise dos resultados, exposição do método de codificação e categorização assumiu-se que a análise qualitativa de dados é caracterizada como um processo indutivo que tem como foco a fidelidade ao contexto de vida dos sujeitos (Alves \& Silva, 1992). Para obtenção dos resultados utilizou-se o método de análise de conteúdo proposto por (Bardin, 1977) que conforme Mozzato e Grzybovski (2011) é uma técnica refinada, que exige dedicação, paciência e tempo do investigador que necessita se valer da intuição, imaginação e criatividade, principalmente na definição das categorias de análise. Bardin (2011) define a análise conteúdo como sendo "Um conjunto de técnicas de análise das comunicações visando obter, por procedimentos, sistemáticos e objetivos de descrição do conteúdo das mensagens, indicadores (quantitativos ou não) que permitam a inferência de conhecimentos relativos às condições de produção/recepção (variáveis inferidas) destas mensagens" (Bardin, 2011, p.47). Antes da análise dos dados propriamente dita, foi realizada a pré-análise (Bardin, 1977). Após a transcrição de todas as respostas para um quadro foi realizada uma primeira leitura leitura flutuante (Bardin, 1977). Em seguida foi realizada uma segunda leitura, desta vez com o intuito de identificar toda e qualquer fala dos entrevistados que se referisse sobre práticas, fases ou qualquer informação que aparentemente estivesse relacionada à GC. Por exemplo: a afirmação "os encontros pedagógicos onde têm esses compartilhamentos de experiências". Nota-se nessa afirmação de um dos entrevistados a possibilidade de "partilha de conhecimento". Dessa forma, os trechos que se referiam à práticas ou ações relacionadas à GC foram extraídos, separados e colocados no quadro para compor a Unidade de contexto (Bardin, 1977). A unidade de contexto "serve de unidade de compreensão para codificar a Unidade de registo e corresponde ao segmento da mensagem, cujas dimensões (superiores às da unidade de registo) são ótimas para que se possa compreender a significação exata da unidade de registo" (Bardin, 2016, p. 137). A Unidade de registo "é a unidade de significação a codificar e corresponde ao segmento de conteúdo a considerar como unidade de base, visando a categorização e a contagem frequencial e efetivamente executam-se certos recortes a nível semântico, o «tema», por exemplo, enquanto que outros se efetuam a um nível aparentemente linguístico, como por exemplo, a "palavra» ou a "frase»" (Bardin, 2016, p. 134). No caso deste estudo, o recorte foi a nível semântico (categoria temática), isto é, a partir dos parágrafos da unidade de contexto extraiuse os temas, que compuseram a unidade de registo, e que a partir desta, deram origem às Subcategorias por temas conforme proposto por (Bardin, 1977). Bardin (2016) define a categorização como sendo uma operação de classificação de elementos que constituem um conjunto por diferenciação e, em seguida, são reagrupados conforme 0 género, isto é, reagrupados por analogia e com critérios previamente definidos. As categorias são classes as quais reúnem um grupo de elementos - unidades de registo - agrupamento esse efetuado em razão de características comuns destes elementos podendo o critério de categorização ser semântico - categoria temática (Bardin, 2016) como foi o caso deste estudo. Dessa forma, a partir do agrupamento dos elementos extraídos das 
falas dos entrevistados, foram constituídas todas as categorias e subcategorias sempre fazendo a vinculação aos objetivos das perguntas totalizando 19 categorias ao todo. Apesar de o estudo completo ter obtido 19 categorias, neste artigo nos concentraremos nos resultados das 15 principais categorias, pois estas possuem relação altamente relevante com objeto de estudo da investigação.

\section{Apresentação dos Resultados}

A constituição dos resultados aqui apresentados se deu a partir da análise do conteúdo das respostas dos participantes, por meio da identificação dos temas em função da frequência da sua ocorrência durante a codificação a partir da unidade de registo. A população-alvo foi dividida em dois grupos: o primeiro grupo composto pelos colaboradores subordinados perfazendo um total de 19 respondentes e o segundo grupo composto pelo colaborador chefe do Departamento constante de 1 respondente. As entrevistas foram realizadas com todos os 20 colaboradores do Departamento alcançando-se $100 \%$ da população-alvo pretendida. A seguir, se passa a apresentar em forma de quadros os resultados conforme as 15 categorias criadas:

\begin{tabular}{|c|c|c|}
\hline Tempo & Instituição & Departamento \\
\hline Entre 6 e 10 anos & $\begin{array}{c}50 \% \\
\text { (10 colaboradores) }\end{array}$ & $\begin{array}{c}20 \% \\
\text { (4 colaboradores) }\end{array}$ \\
\hline Entre 4 e 5 anos & $\begin{array}{c}30 \% \\
\text { (6 colaboradores) }\end{array}$ & $\begin{array}{c}20 \% \\
\text { (4 colaboradores) }\end{array}$ \\
\hline De 0 a 3 anos & $\begin{array}{c}20 \% \\
\text { (4 colaboradores) }\end{array}$ & $\begin{array}{c}60 \% \\
\text { (12 colaboradores) }\end{array}$ \\
\hline
\end{tabular}

\begin{tabular}{|c|l|}
\hline $\begin{array}{c}\text { Frequência } \\
\mathbf{9 0 \%}\end{array}$ & \multicolumn{1}{c|}{ Constatações } \\
\hline $\begin{array}{c}\text { (18 colaboradores) } \\
\text { falar conhecem nenhuma metodologia ou modelo e nunca ouviu }\end{array}$ \\
\hline $\mathbf{1 0 \%}$ & embora não conheçam alguma metodologia ou modelo já \\
\hline $\mathbf{2}$ colaboradores $)$ & ouviram em algum momento falar no tema "gestão do \\
& conhecimento"
\end{tabular}

Quadro 2 - Conhecimento dos colaboradores em relação a metodologias ou modelos de GC 


\begin{tabular}{|c|l|}
\hline \multicolumn{1}{|c|}{ Frequência } & \multicolumn{1}{|c|}{ Constatações } \\
\hline $\mathbf{6 \%}$ das afirmações & há registos que são realizados por meio de atas em reuniões \\
\hline $\mathbf{7 \%}$ das afirmações & $\begin{array}{l}\text { há registos feitos por meio de ferramentas online como o Keep, } \\
\text { Miro e documentos em discos virtuais como Google Drive }\end{array}$ \\
\hline $\mathbf{2 0 \%}$ das afirmações & $\begin{array}{l}\text { existem registos que são feitos por meio dos sistemas } \\
\text { informáticos da Instituição como os Sistema Eletrónico de } \\
\text { Informação (SEI) }\end{array}$ \\
\hline $\mathbf{2 0 \%}$ indica & que há registos feitos de forma direta e indireta \\
\hline $\mathbf{7 \%}$ das afirmações & há registo das atividades, porém não existe acompanhamento \\
contínuo desses registos \\
\hline $\mathbf{4 0 \%}$ das afirmações & $\begin{array}{l}\text { existem registos e acompanhamento das atividades no período da } \\
\text { pandemia da Covid-19 por meio de uma planilha online } \\
\text { compartilhada }\end{array}$ \\
\hline
\end{tabular}

Quadro 3 - Registo e acompanhamento das atividades desenvolvidas pelo colaborador no setor

Fonte: Elaborado pelo autor

\begin{tabular}{|c|l|}
\hline \multicolumn{1}{|c|}{ Frequência } & \multicolumn{1}{|c|}{ Constatações } \\
\hline $\mathbf{1 7 \%}$ das afirmações & $\begin{array}{l}\text { por meio de sistemas de informação da instituição, podendo estes } \\
\text { sistemas serem computadorizados ou não }\end{array}$ \\
\hline $\mathbf{3 5 \%}$ das respostas & $\begin{array}{l}\text { por iniciativa própria do colaborador por meio de documentos } \\
\text { avulsos conforme a demanda }\end{array}$ \\
\hline $\mathbf{1 2 \%}$ das afirmações & $\begin{array}{l}\text { Não há costume ou cultura de todos os colaboradores realizarem } \\
\text { registos }\end{array}$ \\
\hline $\mathbf{1 8 \%}$ afirmam & conhecimento que é registado de maneira informal e indireta por \\
& meio de relatórios, pareceres elaborados por alguns \\
\hline $\mathbf{1 8 \%}$ das respostas & colaboradores \\
\hline
\end{tabular}

Quadro 4 - Perceção quanto às formas de registo do conhecimento criado e adquirido pelo colaborador

\section{Fonte: Elaborado pelo autor}

\begin{tabular}{|c|c|}
\hline Frequência & Constatações \\
\hline $20 \%$ das afirmações & $\begin{array}{l}\text { já houve discussão quanto de mérito para registo de } \\
\text { conhecimento }\end{array}$ \\
\hline $80 \%$ afirmam & $\begin{array}{l}\text { não haver discussão de mérito acerca do conhecimento que se } \\
\text { regista }\end{array}$ \\
\hline
\end{tabular}

Quadro 5 - Discussão de mérito quanto ao conhecimento a ser registado

Fonte: Elaborado pelo autor 


\begin{tabular}{|c|c|}
\hline Frequência & Constatações \\
\hline $11 \%$ das respostas & $\begin{array}{l}\text { afirmam que sistematizam algumas informações quando as } \\
\text { registam }\end{array}$ \\
\hline $28 \%$ das afirmações & $\begin{array}{l}\text { há sistematização realizada parcialmente e com pouca } \\
\text { intencionalidade }\end{array}$ \\
\hline $11 \%$ das afirmações & $\begin{array}{l}\text { é realizada alguma sistematização no período de trabalho remoto } \\
\text { devido a pandemia Covid-19 }\end{array}$ \\
\hline $50 \%$ afirmam & $\begin{array}{l}\text { alguns colaboradores desconhecem se existe alguma forma de } \\
\text { sistematização da informação para o registo }\end{array}$ \\
\hline
\end{tabular}

\begin{tabular}{|c|l|}
\hline \multicolumn{1}{|c|}{ Frequência } & \multicolumn{1}{|c|}{ Constatações } \\
\hline $\mathbf{1 3 \%}$ das respostas & $\begin{array}{l}\text { há iniciativas para elaboração de um documento que defina o } \\
\text { fluxo das informações no Departamento }\end{array}$ \\
\hline $\mathbf{2 0 \%}$ das respostas & $\begin{array}{l}\text { há a necessidade e afirmam que não existe um documento que } \\
\text { defina das informações no Departamento }\end{array}$ \\
\hline $\mathbf{1 3 \%}$ dão conta de que & $\begin{array}{l}\text { há documentos relacionados à questão, mas estes tratam de } \\
\text { maneira específica e isolada alguns fluxos }\end{array}$ \\
\hline $\mathbf{5 4 \%}$ das afirmações & $\begin{array}{l}\text { há colaboradores que desconhecem sobre a existência de } \\
\text { documento oficial que defina o fluxo informacional no } \\
\text { Departamento }\end{array}$ \\
\hline
\end{tabular}

Quadro 7 - Existência de documento oficial da Instituição que define o fluxo informacional

Fonte: Elaborado pelo autor

\begin{tabular}{|c|l|}
\hline \multicolumn{1}{|c|}{ Frequência } & \multicolumn{1}{c|}{ Constatações } \\
\hline $\mathbf{3 5 \%}$ das respostas & $\begin{array}{l}\text { avaliam o uso de SI para apoio ao registo e compartilhamento do } \\
\text { conhecimento como ótimo, excelente ou bom }\end{array}$ \\
\hline $\mathbf{1 8 \%}$ das respostas & $\begin{array}{l}\text { avaliam o uso de SI nesse contexto como útil, importante e/ou } \\
\text { interessante }\end{array}$ \\
\hline $\mathbf{1 2 \%}$ das afirmativas & $\begin{array}{l}\text { avaliam a utilização dos SI para registo e partilha do } \\
\text { conhecimento como positivo }\end{array}$ \\
\hline $\mathbf{2 9 \%}$ das afirmações & $\begin{array}{l}\text { avaliamo uso de SI para registo e partilha do conhecimento como } \\
\text { essencial, fundamental e indispensável }\end{array}$ \\
\hline $\mathbf{6 \%}$ das respostas & $\begin{array}{l}\text { avaliaram a utilização de sistemas de informação para apoio ao } \\
\text { registo e partilha de conhecimento como regular }\end{array}$ \\
\hline
\end{tabular}

Quadro 8 - Perceção do colaborador sobre o uso de sistemas de informação (SI) para apoio ao registo e compartilhamento do conhecimento

Fonte: Elaborado pelo autor 


\begin{tabular}{|c|c|}
\hline Frequência & Constatações \\
\hline $25 \%$ das afirmações & $\begin{array}{l}\text { a Instituição desenvolve ações, mas estas não são relacionadas a } \\
\text { seus cargos }\end{array}$ \\
\hline $\begin{array}{l}37 \% \text { os entrevistados } \\
\text { afirmaram }\end{array}$ & $\begin{array}{l}\text { existem ações, mas são realizadas de forma geral por meio de } \\
\text { cursos de capacitação e formação }\end{array}$ \\
\hline $19 \%$ das afirmações & $\begin{array}{l}\text { há ações da Instituição geralmente mais voltadas para os } \\
\text { colaboradores das áreas administrativas não alcançando áreas } \\
\text { específicas }\end{array}$ \\
\hline $6 \%$ das afirmações & $\begin{array}{l}\text { existem ações de capacitação para os coordenadores de cursos de } \\
\text { nível superior }\end{array}$ \\
\hline $13 \%$ das respostas indicam & $\begin{array}{l}\text { não realiza qualquer forma de ação de estimule a criação e } \\
\text { aquisição de conhecimento pelos colaboradores do Departamento }\end{array}$ \\
\hline
\end{tabular}

Quadro 9 - Estímulo por parte da Instituição para o colaborador adquirir ou criar conhecimento

Fonte: Elaborado pelo autor

\begin{tabular}{|c|c|}
\hline Frequência & Constatações \\
\hline $12 \%$ das afirmações & $\begin{array}{l}\text { existem ações no Departamento, porém estas são promovidas por } \\
\text { iniciativa da equipa de colaboradores }\end{array}$ \\
\hline $18 \%$ das afirmações & $\begin{array}{l}\text { há ações do setor para o colaborador adquirir ou criar } \\
\text { conhecimento e estas ações ocorrem com e sem a participação da } \\
\text { chefia do Departamento }\end{array}$ \\
\hline $23 \%$ das respostas & $\begin{array}{l}\text { que o Departamento desenvolve ações informais e indiretas para } \\
\text { o colaborador adquira ou crie conhecimento }\end{array}$ \\
\hline $47 \%$ das respostas & $\begin{array}{l}\text { disseram que o Departamento não desenvolve ações que visem } \\
\text { estimulá-los a adquirirem ou criarem conhecimento }\end{array}$ \\
\hline
\end{tabular}

Quadro 10 - Perceção quanto ao estímulo por parte do Setor para o colaborador adquirir ou criar conhecimento

Fonte: Elaborado pelo autor 


\begin{tabular}{|c|c|}
\hline Frequência & Constatações \\
\hline $33 \%$ das respostas & $\begin{array}{l}\text { existem ações de estímulo de forma indireta realizadas pelo } \\
\text { Departamento aos colaboradores que trabalham com processos } \\
\text { de suporte }\end{array}$ \\
\hline $13 \%$ das respostas indicam & $\begin{array}{l}\text { que não há ações por falta de tempo específico para esse fim ou } \\
\text { falta de algum tempo destinado ao registo na rotina do } \\
\text { Departamento }\end{array}$ \\
\hline $7 \%$ mostram & $\begin{array}{l}\text { não há ações diretas do setor e os colaboradores realizam registos } \\
\text { por iniciativa própria }\end{array}$ \\
\hline $\begin{array}{l}\text { 47\% das afirmações } \\
\text { indicam }\end{array}$ & $\begin{array}{l}\text { o Departamento não desenvolve ações que estimulem os } \\
\text { colaboradores a realizar o registo de conhecimento }\end{array}$ \\
\hline
\end{tabular}

Fonte: Elaborado pelo autor

\begin{tabular}{|c|c|}
\hline Frequência & Constatações \\
\hline $18 \%$ mencionam & $\begin{array}{l}\text { que existem ações de estímulo para partilha de conhecimento por } \\
\text { parte do Setor com a participação da chefia para que o } \\
\text { colaborador partilhe conhecimento }\end{array}$ \\
\hline $12 \%$ das respostas & $\begin{array}{l}\text { indicam que existem ações de estímulo para partilha de } \\
\text { conhecimento entre coordenadores de curso e em encontro } \\
\text { pedagógicos }\end{array}$ \\
\hline $35 \%$ das afirmações & $\begin{array}{l}\text { afirmam que o setor não desenvolve ações que estimule a partilha } \\
\text { de conhecimento e quando os colaboradores a fazem é por } \\
\text { iniciativa própria }\end{array}$ \\
\hline $35 \%$ das afirmações & $\begin{array}{l}\text { afirmam que o setor não desenvolve de forma alguma ações que } \\
\text { os estimule a partilhar conhecimento }\end{array}$ \\
\hline
\end{tabular}

Quadro 12 - Perceção quanto ao estímulo do Setor para o colaborador partilhar os conhecimentos registados

Fonte: Elaborado pelo autor

\begin{tabular}{|c|l|}
\hline \multicolumn{1}{|c|}{ Frequência } & \multicolumn{1}{|c|}{ Constatações } \\
\hline $\mathbf{7 \%}$ das afirmações & $\begin{array}{l}\text { indicando que a Instituição por vezes impede o colaborador de } \\
\text { aplicar o conhecimento }\end{array}$ \\
\hline $\mathbf{1 3 \%}$ das afirmações & que existem ações sem a participação da chefia do Departamento \\
\hline $\mathbf{1 3 \%}$ expressam & $\begin{array}{l}\text { existe ações de estímulo com a participação da chefia do } \\
\text { Departamento }\end{array}$ \\
\hline $\mathbf{6 7 \%}$ das afirmações & o Departamento não possui uma política de incentivo à aplicação \\
\hline
\end{tabular}

Quadro 13 - Perceção quanto ao estímulo do setor para o colaborador aplicar/utilizar o conhecimento 


\begin{tabular}{|c|} 
Constatação \\
\hline - Não possui conhecimento se os colaboradores elaboram manuais para registo do \\
conhecimento produzido no Departamento. \\
Quadro 14 - Perceção da Chefia do Departamento quanto à realização de registos do conhecimento \\
produzido pelos colaboradores
\end{tabular}

Fonte: Elaborado pelo autor

\section{Constatação}

- Não possui conhecimento se os colaboradores elaboram manuais para registo do conhecimento produzido no Departamento;

- Vê a necessidade de ações de capacitação aos gestores;

- Considera que pode e deve estimular os colaboradores a adquirir, criar e registar novos conhecimentos.

Quadro 15 - Visão da Chefia do Departamento quanto à possibilidade de ações de estímulo aos colaboradores subordinados para adquirirem, criarem e registarem novos conhecimentos

\section{Discussão dos Resultados}

Se apresenta a seguir as discussões acerca dos principais resultados obtidos no trabalho de campo procurando responder às questões de investigação que por sua vez estão vinculadas aos objetivos do estudo.

Em relação à primeira categoria "Tempo de experiência dos colaboradores no setor e na instituição", cujo objetivo do estudo era ter uma noção básica sobre o tempo de experiência profissional dos colaboradores na instituição, observou-se que a maior parte dos colaboradores tem mais tempo de experiência na instituição em geral do que no Departamento de Apoio ao Ensino.
Em relação à categoria 2 "Conhecimento dos colaboradores em relação a metodologias ou modelos de GC", cujo objetivo era perceber se alguns dos colaboradores tinham alguma consciência sobre práticas ou ferramentas de GC e alguma atividade em função desse conhecimento, foi possível observar que $90 \%$ não conhecem nenhuma metodologia ou modelo, prática ou ferramenta de GC e nunca ouviu falar sobre o tema enquanto que $10 \%$ embora não conheçam algum modelos ou práticas já ouviram em algum momento falar no tema "gestão do conhecimento".

Em relação à categoria 3 "Registo $e$ acompanhamento das atividades desenvolvidas pelo colaborador no setor", 
cujo objetivo deste estudo foi identificar se os colaboradores realizavam registos das atividades que desenvolviam no Departamento, observou-se que os colaboradores realizam alguns registos das suas atividades que são feitos por meio de atas em reuniões, ferramentas online como o Keep, Miro e discos virtuais como Google Drive e ainda os registos que são feitos por meio dos sistemas de informações da Instituição como os Sistema Eletrónico de Informação (SEI). Essas informações poderão posteriormente ser acedidas e serem transformadas em conhecimento e agregado aos processos da organização.

Em relação à categoria 4 "Perceção dos colaboradores quanto às formas de registar o conhecimento criado por eles no Departamento", cujo objetivo deste estudo foi conhecer como eram realizados esses registos e conhecer se havia uma política instituída para os colaboradores registarem o conhecimento produzido, foi possível observar que a maioria dos colaboradores, para além de registar as atividades desenvolvidas, realizam também alguns registos do conhecimento que vão adquirindo com o passar do tempo no setor. Entretanto, vê-se que esses registos são realizados por iniciativa própria, sem um direcionamento formal, por meio de documentos avulsos conforme a demanda utilizando os sistemas de informação, computadorizados ou não, da Instituição como o Sistema Eletrónico de Informação (sistema de gereciamento de processos), sistema Redmine (gerenciador de projetos) e até mesmo em pastas compartilhadas em nuvem.

Em relação à categoria 5 "Discussões de mérito quanto ao conhecimento que os colaboradores registam
Departamento", cujo objetivo deste estudo foi compreender se havia algum tipo de discussão quanto ao grau de importância do conhecimento que se regista, foi possível observar que os colaboradores, em raros casos, realizam alguma discussão de mérito para registo do conhecimento. Em maior parte, foi observado que não há discussão quanto ao mérito, isto é, quanto ao valor e viabilidade do conhecimento para o seu registo.

Em relação à categoria 6 "Processo de sistematização da informação desenvolvida pelos colaboradores do Departamento" descobriu-se que é pouco provável que haja um processo intencional no sentido de gerenciamento do conhecimento. Em outras palavras, os resultados mostram que quando os colaboradores fazem alguma forma de sistematização da informação, eles a fazem sem a perceção plena de que essa sistematização será útil ao processo gerenciamento do conhecimento.

Quanto à categoria 7 "Possibilidade de existência de documentos oficiais da Instituição que definam os fluxos de informações no Departamento", cujo objetivo deste estudo foi de verificar se existem documentos oficiais orientando o fluxo das informações no setor pelos quais os colaboradores poderiam se nortear, verificou-se que existem iniciativas dos gestores para oficializar, a partir da elaboração de documentos, os fluxos já existentes. Parcebeu-se que a partir de suas experiências profissionais alguns dos colaboradores entrevistados reconhecem a necessidade de documentos que definam os fluxos das informações e afirmam que atualmente não existem documentos com essa finalidade. 
Em relação à categoria 8 "Perceção dos colaboradores sobre o uso de SI para apoio ao registo e partilha do conhecimento", cujo objetivo neste estudo foi de conhecer como os colaboradores avaliam a utilização de sistemas de informação, sejam eles computadorizados ou não, para o registo e compartilhamento do conhecimento, observou-se que os entrevistados percebem de forma muito positiva e classifica o seu uso como essencial, fundamental, indispensável.

Com relação à categoria 9 "Possibilidade de estímulo da Instituição para que os colaboradores possam adquirir ou criar conhecimento", cujo objetivo deste estudo foi de conhecer se a Instituição de alguma maneira desenvolve ações com a finalidade de estimular o interesse dos colaboradores do Departamento a criar conhecimento, observou-se que existem ações de estímulo por parte da Instituição para que o colaborador do Departamento possa criar conhecimento. Entretanto, observou-se que a maior parte dos estrevistados acreditam que as ações de estímulo são disponibilizadas de forma bastante geral como, por exemplo, os programas de incentivo à qualificação profissional em áres genéricas do conhecimento e não diretamente relacionadas ao cargo ou atividade que o colaborador desempenha.

Em relação à categoria 10 "Perceção dos colaboradores quanto à possibilidade de estímulo do Departamento para o colaborador adquirir ou criar conhecimento", cujo objetivo deste estudo foi de identificar se existem ações do Departamento nesse sentido, verificou-se que a maior parte dos colaboradores defendem que o setor não desenvolve ações que visem estimulá-los a adquirem ou criarem conhecimento.
Em relação à categoria 11 "Possibilidade de ações de estímulo do Departamento para os seus colaboradores registarem os novos conhecimentos", cujo objetivo deste estudo foi de identificar se o Departamento desenvolve ações que estimulem, de alguma maneira, os colaboradores a registarem o conhecimento que adquirem no desenvolvimento de suas atividades, destaca-se que a maioria dos entrevistados possuem a perceção de que o Departamento não desenvolve ações nesse sentido.

Em relação à categoria 12 "Perceção dos entrevistados quanto ao possível estímulo do Setor para o colaborador partilhar os conhecimentos adquiridos e registados", cujo objetivo deste estudo foi de compreender se o Departamento, de alguma forma, desenvolve ações que estimule os colaboradores a partilhar 0 conhecimento que adquirem, observou-se que este não desenvolve ações que estimule a partilha de conhecimento entre os colaboradores. É importante mencionar que uma pequena parte dos entrevistados mencionaram que percebem, de certa forma, algum estímulo envolvendo a gestão do setor, isto é, a chefia do Departamento, mas de maneira informal.

Em relação à categoria 13 "Perceção dos entrevistados sobre possíveis ações de estímulos do Departamento para que seus colaboradores pratiquem a utilização dos conhecimentos por eles gerados" em que o objetivo neste estudo foi de identificar se o Departamento desenvolve ações que estimule os colaboradores a aplicar ou utilizar o conhecimento que adquirem, observou-se que uma porção bastante grande dos entrevistados julgam que 0 Departamento não possui uma política de incentivo à aplicação do conhecimento. 
Em relação à categoria 14 "Perceção da Chefia do Departamento quanto à realização de registos do conhecimento por parte dos colaboradores subordinados", cujo objetivo desse estudo foi de identificar como a Chefia do Departamento percebia a atuação dos colaboradores quanto ao registo do conhecimento produzido por eles no dia a dia no setor, observou-se que a chefia possui a perceção de que no período da pandemia da Covid-19 os colaboradores realizam alguns registos em planilha online compartilhada. Entretanto, fora desse período da pandemia, a chefia observa que não possui conhecimento se os colaboradores subordinados realizavam algum tipo de registo dos conhecimentos produzidos no setor.
Em relação à última categoria "Visão da chefia do Departamento sobre a possibilidade de desenvolvimento de ações para estimular os colaboradores subordinados a realizarem práticas de GC", em que o objetivo deste estudo foi conhecer a perceção do gestor do Departamento quanto à possibilidade de influenciar os seus subordinados nas práticas de GC e apurar se de alguma maneira a chefia do Departamento já realizava alguma ação nesse sentido, observou-se que o gestor entende que não desenvolve ações de incentivo aos colaboradores subordinados a adquirirem, criarem, registarem e partilharem conhecimento. Entretanto, reconhece que essas ações de estímulos se configuram com possibilidades necessárias.

\section{Conclusões}

A partir da discussão dos resultados se concluiu que foi possível alcançar as respostas pretendidas às questões de investigação inicialmente propostas neste estudo visto que foi possível conhecer a perceção dos colaboradores acerca da possibilidade de práticas de GC no Departamento. Os colaboradores percebem que há diversas pequenas práticas de GC como registos eventuais do conhecimento criado por eles, eventuais momentos de partilha do conhecimento entre colaboradores e a criação de conhecimento no desenvolvimento das atividades no dia a dia. Percebem ainda que essas ações geralmente são realizadas sem a intenção de se fazer práticas de GC uma vez que os colaboradores não têm conhecimento do que é a GC. Também se descobriu que o Departamento gera conhecimento tácito ao passo que os colaboradores criam modelos mentais no dia a dia, bem como também geram conhecimento explícito quando elaboram manuais, tutoriais $\mathrm{e}$ elaboram relatórios de trabalho nos sistemas da instituição. Uma questão bastante importante que foi respondida a partir da análise dos dados é a de foi possível evidenciar algumas recomendações ao Departamento estudado das quais se destacam: a) promover a participação dos colaboradores em palestras, workshops e outros eventos sobre GC para melhor entendimento sobre sua importância para as organizações; b) criar grupos de estudo sobre o tema Gestão Conhecimento e suas particularidades; c) realizar mapeamento dos processos do Departamento; d) prover a participação dos colaboradores em programas de capacitação sobre o uso dos sistemas de informação da Instituição; e) implementar 
reuniões periódicas com os colaboradores para a partilha de experiências vivenciadas; f) incentivar e criar possibilidade de cursos de capacitação para as áreas dos cargos dos colaboradores; g) discutir e rever a própria prática em relação às ações de estímulo aos colaboradores nas práticas de GC; $h$ ) promover a aproximação do Departamento com o setor de RH para discussão de práticas de $\mathrm{GC}$ e; i) participação do gestor em eventos de capacitação para gestão de equipas.

Quanto às contribuições trazidas por este estudo acredita-se que os resultados encontrados possivelmente serão úteis a gestores de organizações principalmente de organizações públicas no país, e em especial para implementação de modelos e práticas de GC com foco nos princípios da eficiência da Administração Pública. Percebeu-se que a grande maioria das organizações públicas brasileiras ainda não possuem modelos e práticas de GC formalmente instituídas, estas desenvolvem pequenas ações relacionadas a GC no dia a dia, porém não se têm consciência disso.

Em relação às limitações encontradas ao desenvolver este estudo destaca-se o fator "tempo" que por causa do período de isolamento e distanciamento social devido à pandemia da Covid-19 que causou mudanças bruscas nos hábitos em diversas áreas da população mundial afetando também a atuação do investigador e todos os envolvidos na investigação. Nesse período perdeu-se considerável espaço de tempo (três ou quatro meses) nas tentativas de adaptações das rotinas de vida. Embora, houve tais limitações considera-se que os resultados esperados foram devidamente alcançados e satisfatórios do ponto de vista investigativo.

A partir dos resultados da investigação empírica trazidos à luz neste estudo outros interessados no assunto poderão investigar de forma mais direta sobre possíveis práticas de GC que colaboradores desenvolvem podendo até mesmo, se for o caso, propor a implementação de algum modelo ou pequenas práticas de $\mathrm{GC}$ a fim de dar início a processos institucionalizados de Gestão do Conhecimento em alguma organização. É importante considerar também a possibilidade novos diagnóstico em outros tipos de setores de organizações públicas, que não sejam intensivas em conhecimento, a fim de comparar os resultados. 

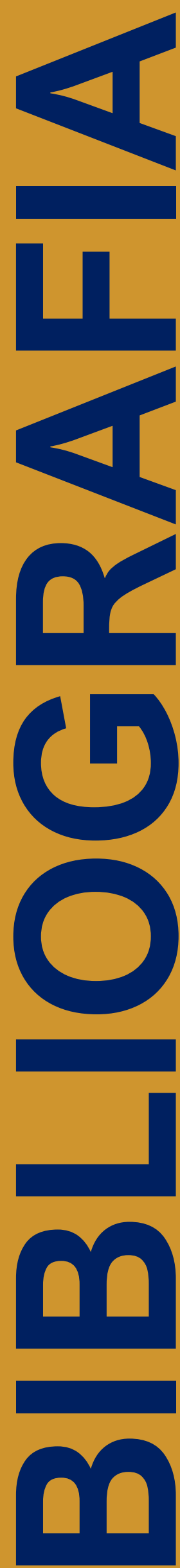

Alves, Z. M. M. B., \& Silva, M. H. G. F. D. da. (1992). Análise qualitativa de dados de entrevista: uma proposta. Paidéia (Ribeirão Preto), 2, 61-69. https://doi.org/10.1590/s0103863x1992000200007

Arvani, M. R. de A. (2018). Diagnóstico da Gestão do Conhecimento: estudo de caso em uma instituição pública brasileira. 80 .

Bardin, L. (1977). Análise de conteúdo. Edições 70. https://www.ets.ufpb.br/pdf/2013/2 Metodos quantitat e qualitat IFES/Bauman, Bourdieu, Elias/Livros de Metodologia/Bardin 1977 - Análise de Conteúdo.pdf

Bardin, L. (2011). Análise de conteúdo. Edições 70.

Bardin, L. (2016). Análise de Conteúdo. Almedina Brasil.

Basso, L. M. (2017). Desafios da gestão do conhecimento no setor público: Um estudo bibliométrico no portal Capes. https://doi.org/10.1017/CBO9781107415324.004

Batista, F. F., \& Quandt, C. O. (2015). Gestão do conhecimento na administração pública - resultados da pesquisa IPEA 2014. Journal of Chemical Information and Modeling, 53(9), 117. https://doi.org/10.1017/CBO9781107415324.004

Braun, C. C., \& Mueller, R. R. (2014). A gestão do conhecimento na administração pública municipal em Curitiba com a aplicação do método OKA - Organizational Knowledge Assessment. Revista de Administração Pública, 48(4), 983-1006. https://doi.org/10.1590/0034-76121620

Davenport, T., \& Prusak, L. (1999). Conhecimento Empresarial (10a). Campus.

Fleury, M. T. L., \& Oliveira, M. de M. J. (2017). Gestão Estratégica Do Conhecimento: Integrando Aprendizagem, Conhecimento E Competências (1a). Atlas.

Gil, A. C. (2002). Como elaborar projetos de pesquisa (4a Edição). Atlas. https://doi.org/10.1007/978-1-137-49662-1

Helou, A. R. H. A. (2015). Avaliação da maturidade da gestão do conhecimento na administração pública. 373 .

Krogh, G. von, Ichijo, K., \& Nonaka, I. (2001). Facilitando a criação de conhecimento. Campus.

Magalhães, A. (2017). A gestão do conhecimento nas Organizações Militares Prestadoras de Serviços Industriais (OMPS-I) da Marinha do Brasil: o papel da gestão de recursos humanos.

https://repositorium.sdum.uminho.pt/handle/1822/46512

Marconi, M., \& Lakatos, E. (2003). Fundamentos de metodologia científica. In Editora Atlas S. A. (5a). Atlas. https://doi.org/10.1590/S1517-97022003000100005 
Motta, P. R. de M. (2013). O estado da arte da gestão pública. 82-90.

Mozzato, A. R., \& Grzybovski, D. (2011). Análise de Conteúdo como Técnica de Análise de Dados Qualitativos no Campo da Administração: Potencial e Desafios. Revista de Administração Contemporânea, 04, 731-747. https://www.scielo.br/pdf/rac/v15n4/a10v15n4.pdf

Nonaka, I., \& Takeuchi, H. (1997). Criação de Conhecimento na Empresa: Como as Empresas Japonesas Geram a Dinâmica da Inovação (10a). Campus.

MtoTODO

Paludo, A. V. (2016). Administração pública (5a).

Pinto, J. A. de S. (2015). Um modelo para a gestão do conhecimento organizacional no contexto dos serviços partilhados com recurso à utilização do e-Learning.

Setim, C. R. B. (2019). Análise econômica das decisões da Administração Pública. 05, 107-127. https://www.nucleodoconhecimento.com.br/administracao/anali se-economica

Silva, A. R. A. da. (2018). A Gestão do Conhecimento aplicada à Administração Pública. 03, 5-13. https://www.nucleodoconhecimento.com.br/wpcontent/uploads/artigo-cientifico/pdf/gestao-doconhecimento.pdf

Sociedade Brasileira de Gestão do Conhecimento. (2014). O que é Gestão do Conhecimento? Sociedade Brasileira de Gestão Do Conhecimento. http://www.sbgc.org.br/blog/o-que-egestao-do-conhecimento

Sohn, A. P. L., Vieira, F. D., Casarotto Filho, N., \& Souza, J. A. (2013). Gestão Estratégica do Conhecimento: Uma Proposta de Formação Profissional. Revista de Ensino de Engenharia, 32(2), 31-38. https://doi.org/10.15552/22360158/abenge.v32n2p31-38

Souza, M. T. de, Silva, M. D. da, \& Carvalho, R. de. (2010). Integrative review: what is it? How to do it? Einstein (São Paulo), 8(1), 102-106. https://doi.org/10.1590/s1679-45082010rw1134

Stewart, T. A. (1998). Capital Intelectual - A Nova Vantagem Competitiva das Empresas (A. B. Rodrigues \& P. M. Celeste (eds.); 5a). Campus.

Takeuchi, H., \& Nonaka, I. (2008). Gestão do Conhecimento. Bookman.

Vianna, C. T., Alvaro, F., Gauthier, O., Andrade, J. T., Costa, R., \& Schutz, S. M. (2017). Bukowitz \& williams: diagnóstico de gestão do conhecimento em uma incubadora. VII Congresso Internacional de Conhecimento e Inovação, 1-15 